Western University Scholarship@Western

1975

\title{
Land Reform: Some Theoretical Considerations
}

Mark Gersovitz

Follow this and additional works at: https://ir.lib.uwo.ca/economicsresrpt

Part of the Economics Commons

Citation of this paper:

Gersovitz, Mark. "Land Reform: Some Theoretical Considerations." Department of Economics Research Reports, 7518. London, ON: Department of Economics, University of Western Ontario (1975). 
Research Report 7518

IAND REFORM: - SOME THEORETICAL

CONSIDERATIONS

Mark Gersovitz

August, 1975 
IAND REFORM: SOME THEORETICAL CONSIDERATIONS

By Mark Gersovitz*

This paper discusses alternative explanations of the empiri-

cally established inverse relation between the size of farm and

the output-land and labor-1 and ratios used in agricultural pro-

duction in LDC's. The analys is establishes the implications

of the various explanations for changes in income distribution

and agricultural output associated with different types of 1 and

reform programs. These implications are rather heterogeneous,

and are extremely sensitive to the particular explanation of

the production ratio pattern which is adopted.

I. Some Issues in the Theory of Land Reform

This paper presents a theoretical discussion of land reform. No attempt is made to encompass the full diversity of the land reform problem; every problem is not investigated with each model. Rather, the implications of a limited number of different pre-reform situations and reform schemes for distribution and production are examined using a consistent analytical approach. The approach adopted bears much in common with previous work on agricultural decision making units undertaken in the context of the surplus labor issue, for example [Sen, 1966]. It is hoped that the framework which is thus established will prove useful in the analysis of other pre-reform situations and reform schemes. The basic mode of inquiry is comparative statics, and many dynamic phenomena

*University of Western Ontario. I am grateful to R. J. Arnott, Robert E. Evenson and James L. McCabe for their comments on an earlier draft of this paper. 
are lost to view. However, so little attention has been paid to those aspects of land reform which are susceptible of rigorous analysis that this approach seems well worthwhile. Where appropriate, we indicate implications of the models for empirical projection (of the type developed in [C1jne, 1970]) of the impact of a land reform.

A large empirical literature [Dorner and Kanel, 1971] discusses evidence on the relationship between farm size (measured in acres) and output in less developed countries. The consensus is that there exists an inverse relation between farm size and output per acre. Further, there is some evidence [Dorner, 1972, PP. 101-103] of an inverse relation between the labor-land ratio and farm size. These empirical relationships have been widely construed as justifying land reforms which break up large holdings as likely to increase agricultural output. The optimistic view [Dorner, 1971, P. 141 and Long, 1961, p. 115] is that income equalization and increased production are compatible.

A more pessimistic conclusion has been reached in a model with three groups (landless laborers, small farmers and large landowners). In this context, it is argued [Berry, 1971, P. 32] that "while land redistribution may be expected to raise agricultural output in many cases, it may well worsen the distribution of income by lowering the demand for hired labour."

Before the relationship between land reform, income distribution and production can be established, it is imperative that the mechanism by which farms of different sizes operate with different output-1 and and 1 abor-land ratios is explicitly integrated into the analysis. Anong the reasons given for the observed differences in these ratios four will be considered. For ease of reference, they may be labelled as the measurement, market failure, large 1andowner inefficiency and landowner-monopsonist explanations. Alternative explana- 
tions stress risk factors [Srinivasan, 1972] or that farm size influences access to cheap capital, ${ }^{1}$ a factor of production which is suppressed in our analysis. Two basic pre-reform situations with correspondingly different land reform schemes may be distinguished. In the simplest (A) case, there are only two groups, landowners and landless laborers. Since there are no small farms, any assessment of production ratio differences between different sized farms must base itself on cross-country comparisons. It is assumed that production ratio relationships observed in countries with small farms would be valid in the country under consideration if it were also to have a small farm sector. Alternatively, the country under consideration may be assumed to have a small farm sector which is insignificant in size, but whose behavior nonetheless substantiates the expected production ratio pattern. Under either interpretation, the relevant land reform scheme is one of all land to the landless laborers.

The second pre-reform situation is the Berry (B) case, with landowners, small (landowning) farmers and landless laborers. In this case, the land reform scheme is one of all land to the small farmers. A scheme which re-allocated land to both small farmers and landless laborers would be similar to case A. Thus, the $A$ and $B$ cases can be considered as polar situations.

Other important characteristics of the reform program are its extensiveness and provisions for compensation. We designate reforms as total if all land in large units is redistributed to small units while reform is partial if large landowners retain part of their former holdings. Two poles of compensation policy will be examined: (1) outright confiscation of all land redistributed and (2) full payment of all rents formerly accruing to former owners of redistributed land or to the government. 
Unless explicitly indicated, the agricultural sector under examination is assumed to be part of an economy which is small relative to the world economy. Consequently, the relative price of agricultural and non-agricultural goods are assumed constant, permitting the suppression of non-agricultural goods in the analysis. Initially, it is assumed that labor is immobile between the agricultural and non-agricultural sectors. This assumption is subsequently removed without qualifying the results.

In Section II, we consider some total reforms in which land is confiscated outright and attention is given to the decision individuals make between leisure and consumption.' Section III discusses partial reforms and section IV comments on the compensation issue. Section $V$ presents genera1-equilibrium, intersectoral considerations. 
II. Distribution and Production Implications of Some Total Land Reforms

A. Land Reform and the Measurement Explanation

A measurement explanation of the difference in production ratios simply asserts that land is inhomogeneous and that this inhomogeneity leads to the observed production ratio relationships. Under assumptions of perfect competition, all farms would operate with the same production ratios when land is measured in fertility equivalent acres. In empirical work, despite attempted corrections, land is basically measured in yardstick acres, and farms composed of less fertile land will have lower output-land and labor-land ratios.

Further, there is a tendency for farms whose land is less fertile to dominate the larger size groups. Consider a simple case with only two grades of land, type one of superior fertility and type two of inferior fertility. Suppose that the distribution of farm size functions for farms composed of the two types of land are identical when farm size is measured in fertility equivalent acres. However, insofar as farms are measured in yardstick acres, farms with type two land and low production ratios tend to dominate the large size classes.

While the assumption of inhomogeneous land provides a complete explanation for observed variations in production ratios, it is fully compatible with the usual competitive assumptions. Indeed, when land is measured in equivalent fertility acres, the inhomogeneous land model reduces to the simple competitive. model. For convenience, therefore, all land is assumed to be standardized. The analysis is relevant to both the competitive case and to the inhomogeneous land case after a retranslation of results from standard to yardstick acres. In Figure 1, the pre-reform equilibrium of the agricultural sector is illustrated under case A assumptions. Output as a function of labor input, 


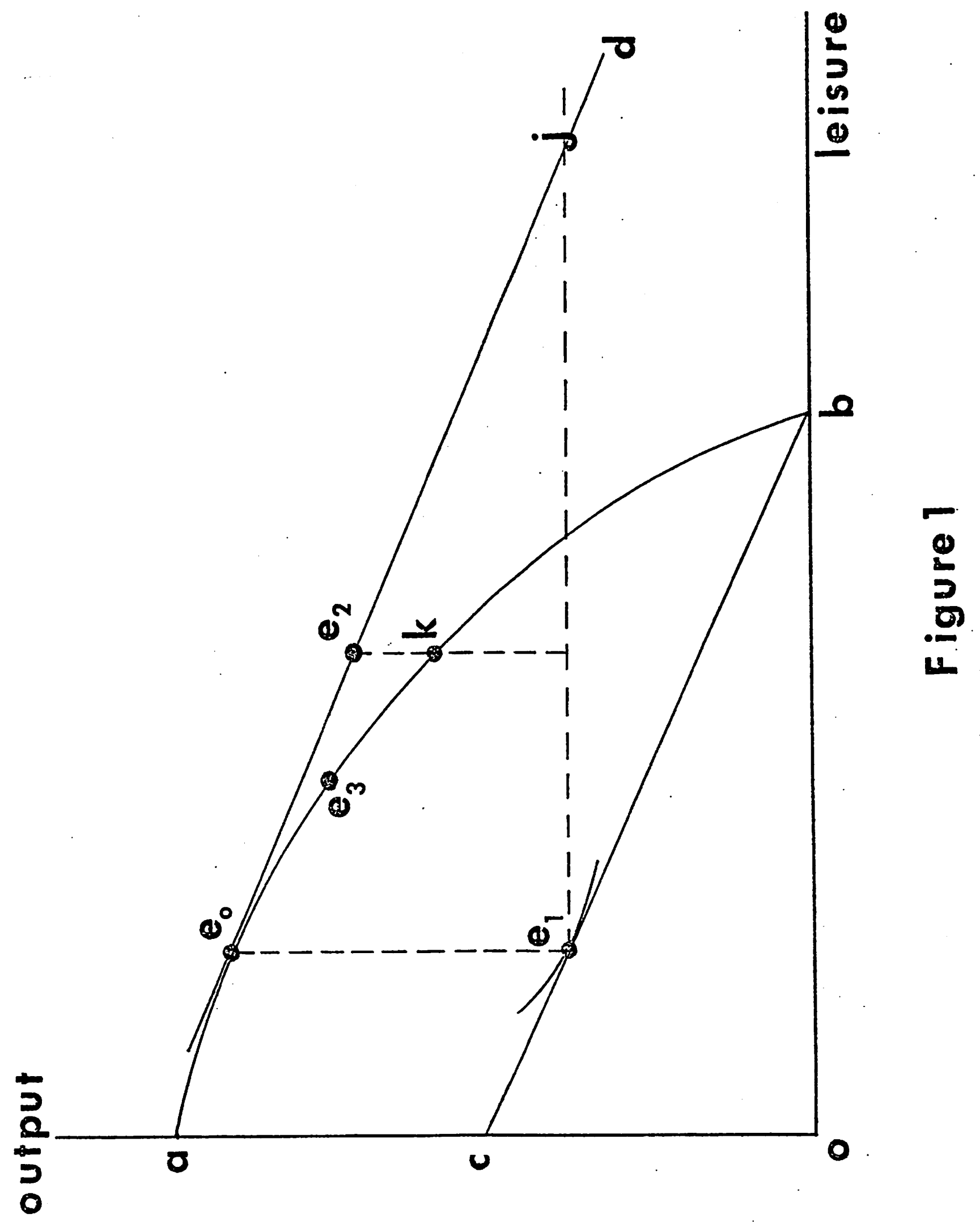


given the amount of land, is given by the curve ab . Labor input is measured from right to left starting at the origin $b$. The production function $a b$ can then be interpreted as a production possibility frontier between agricultural output and leisure with respect to the origin 0 . ob is the total amount of time available to the landless laborer community. A set of this group's community indifference curves is plotted with origin 0 . The wage is assumed equal to the marginal product of labor given by the slope of the line $e_{0} d$ equal to the slope of the line $c b$. Equilibrium will be characterized by two points such as $e_{0}$ and $e_{1}$, with demand for labor equal to supply of labor.

Now consider a land reform which transfers all land to the land less laborers. Assume that neither leisure nor agricultural goods is inferior. At a (shadow) wage given by the slope of the old wage line $e_{0} d$, the landless laborer community will reach the highest level of utility somewhere along $e_{0} j$, say at $e_{2}$. This position is not, however, a final equilibrium since the production of leisure and the agricultural good (given by point $e_{0}$ ) is not equal to the demand for leisure and the agricultural good (given by point $\left.e_{2}\right)$. Final equilibrium is attained at some point along the arc $e_{0} k$, say at $e_{3}$. At $e_{3}$, the total output of the agricultural good has fallen. Consumption (and welfare) of the landless laborers has, of course, increased. Equilibrium under case $B$ assumptions is illustrated for the small farmer and landowner sectors in Figures 2 and 3 respectively. In Figure 2 the small farmer group's indifference map is drawn with origin 0 , curve $A B$ is a production possibility frontier giver the amount of land held by small farmers and total time available to small farmers is $O B$. With the equilibrium wage given by the slope of $E_{0} D$ (equal to the slopes of $e_{0} d$ and $c f$ in Figure 3 ), 


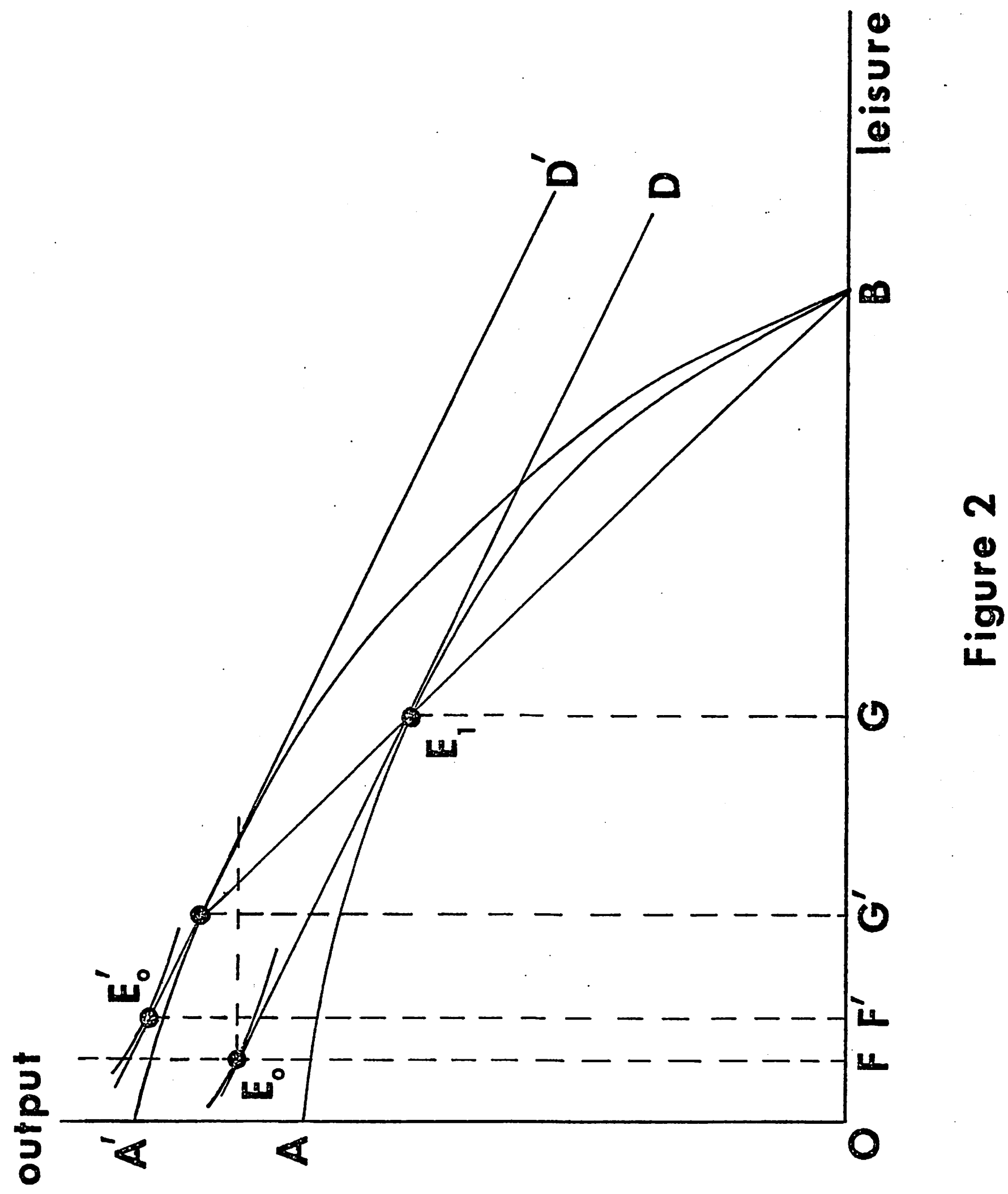




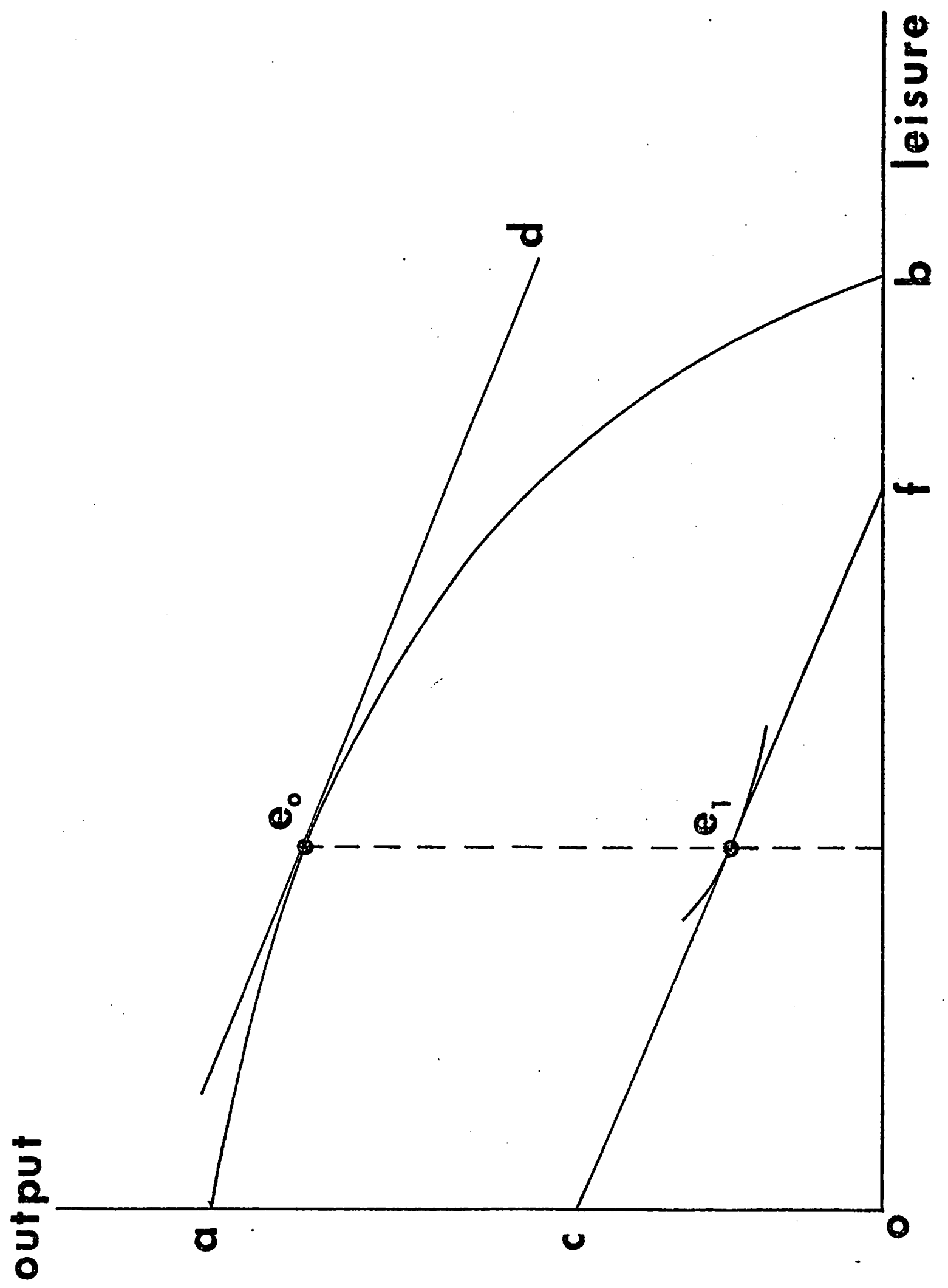

ค2 
small farmers wish to work FG (equal to $\mathrm{fb}$ in Figure 3 ) hours on the landowners' land.

In Figure 3, the landless laborer group is assumed to have an indifference map with origin $0, a b$ is a production possibility frontier given the amount of land owned by landowners, and total time available to landless laborers is of . Equilibrium is given by a pair of points $e_{0}$ and $e_{1}$ with demand for labor on the part of landowners equal to the supply of labor from small farmers and landless laborers.

Now consider a land reform scheme which transfers all land to the small farmers. The consequent shift out in the production possibility frontier (to $A^{\prime} B$ in Figure 2) facing the small farmers leads to a decline in the amount of work they are willing to perform at any wage if leisure is a normal good (e.g., in Figure 2, at wage given by slopes of $E_{0}^{\prime} D^{\prime}$ and $E_{0} D$, equilibrium is at $\mathrm{E}_{0}^{\prime}$ versus $\mathrm{E}_{0}$ ).

A supply of labor function can be defined as the sum of the work done by landless laborers and that done by small farmers (given the amount of land they own) at any wage rate. Other factors given, each group's labor supply is assumed to be an increasing function of the wage; backward bending 1 abor supply functions are ruled out. A demand for labor function can be defined as the sum of the amount of labor used on the land originally belonging to small farmers and on that originally belonging to landowners. In the case under consideration, the fall in labor supplied by the small farmers shifts the supply of labor function up. The demand for labor schedule, determined by the marginal product of labor (given the total amount of land) remains constant. As a result, the wage rises, output falls and both small farmers and landless laborers are better off. 


\section{B. Land Reform and the Market Failure Explanation}

A market failure explanation of the differences in production ratios concentrates on imperfections in the land and labor markets in LDC agricultural sectors. Many small farmers, given the amount of land they own, the wage rate and the rental rate on land, would like either to rent more land or to allocate part of their time to working off their farms. Opportunities for factor ratio adjustments may, however, be limited or unavailable. Small farmers are then confined to working their own land.

Equilibrium of small farmers under market failure is illustrated in Figure 4 which repeats the information on the small farms contained in Figure 2. Under the assumption of market failure, however, equilibrium cannot occur at $E_{0}$ since $E_{0}$ implies that small farmers work $F G$ hours on the farms of large landowners. Without this opportunity, equilibrium is reached somewhere along the arc $\mathrm{HE}_{1}$, say at $\mathrm{E}_{2}$.

Equilibrium in the landowner-laborer sector is illustrated by Figure 1. The marginal product of labor in the landowner sector (given by the slope of $e_{0} d$ in Figure 3, equal to the slope of $E_{1} D$ ) exceeds that in the small farm sector (given by the slope of $A B$ at $E_{2}$ ). On assumptions of constant returns to scale and identical production functions in the two sectors, the output-land and labor-land ratios are higher in the small farm sector. Since the representation of the landowner sector under the market failure and measurement explanations is identical, case A land reform has the same outcome under both sets of assumptions.

Case B land reform is, however, considerably more complicated. Consider the post-reform wage. At a wage less than or equal to the wage given by the slope of $A B$ at $E_{2}$, small farmers will do less work than prior to the reform 


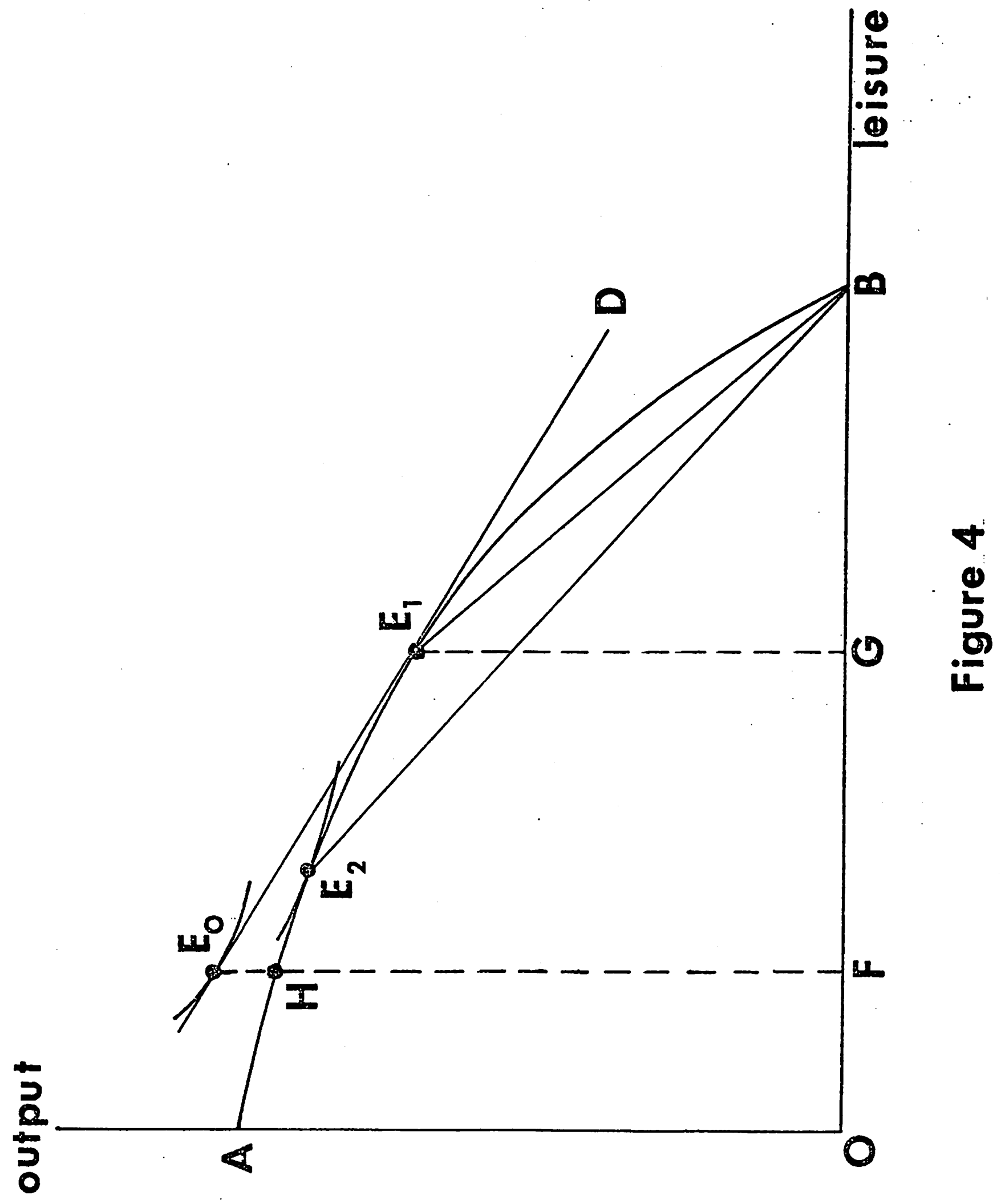


since they now own more land. Since this wage is less than that received by landless laborers in the pre-reform situation, laborers also supply less labor. Yet, since both the land formerly held by landowners and that originally held by small farmers is worked more intensively, the demand for labor is higher at this wage than in the pre-reform situation. Hence, at a wage lower than that associated with point $E_{2}$, demand for labor exceeds the supply of labor and equilibrium is impossible.

At a wage between that implied by $E_{2}$ and the pre-reform wage given at $E_{1}$, the supply of labor by laborers continues to fall short of its pre-reform level. Small farmers, however, may wish to work more than previously. Two offsetting factors influence the small farmers. The implicit wage is now more favorable than that which they were receiving at $\mathrm{E}_{2}$, but the additional income derived from their new lands acts to discourage additional work. Similarly, the demand for labor may increase or decrease. The lands which were always owned by the small farmers are now worked less intensively, while the newly acquired lands are worked more intensively. Consequently, it is possible to have an equilibrium in which post-reform wages are lower than at $E_{1}$ (but higher than at $E_{2}$ ), landless laborers are worse off and either more or less output is produced relative to the pre-reform situation.

For wages exceeding the pre-reform wage, laborers wish to supply more labor than previously. Small farmers may or may not wish to work more; their decision is based on the same considerations discussed above. Less labor is demanded since both the newly acquired and the original small farmer lands are worked less intensively. Consequently, it is possible for the post-reform equilibrium to be characterized by higher wages and an improvement in landless laborer welfare. Less output is produced. Thus, under the market failure 
hypothesis it is impossible for reform to increase both output and landless laborer welfare.

C. Land Reform and the Inefficiency Explanation

An inefficiency explanation asserts that large, often absentee, landowners fail to operate in a rent maximizing fashion. The equilibrium of the small farm sector under the inefficiency hypothesis is identical with its position as illustrated in Figure 2. Figure 5 reproduces Figure 3 with the important additional assumption of landlord inefficiency.

Consider an equilibrium wage given by the slope of $e_{0} d$ equal to the slopes of $g b$ and $c f$ (and to that of $E_{0} D$ in Figure 2). Under the usual assumptions of efficiency and competition, with small farmers working fb (equal to FG in Figure 2) hours on landowners' land, landless laborers must be in equilibrium at point $e_{1}$ if $e_{0} d$ is to define the equilibrium wage. Otherwise, the demand for labor (given by the marginal product of labor) would not equal the supply of labor from small farmers and landless laborers. Under an inefficiency hypothesis, no such restriction can be placed on the equilibrium position since the demand for labor is no longer given by the marginal product of labor.

Certain a priori restrictions can, however, be placed on the equilibrium position. Given the equilibrium wage, landless laborers must be in equilibrium somewhere along cf. Total wage payments for any amount of labor along bo, say $\mathrm{bl}$, are given by the height of the line $\mathrm{gb}$ corresponding to that amount of labor $\left(e_{3} l\right.$ in the case of bl). Now, if landowners do not run their. farms at a loss, the total amount of output produced must at least cover the wage bill (i..e., production must be along the segment he 3 in the case of b1). These considerations restrict the production point (combination of labor 


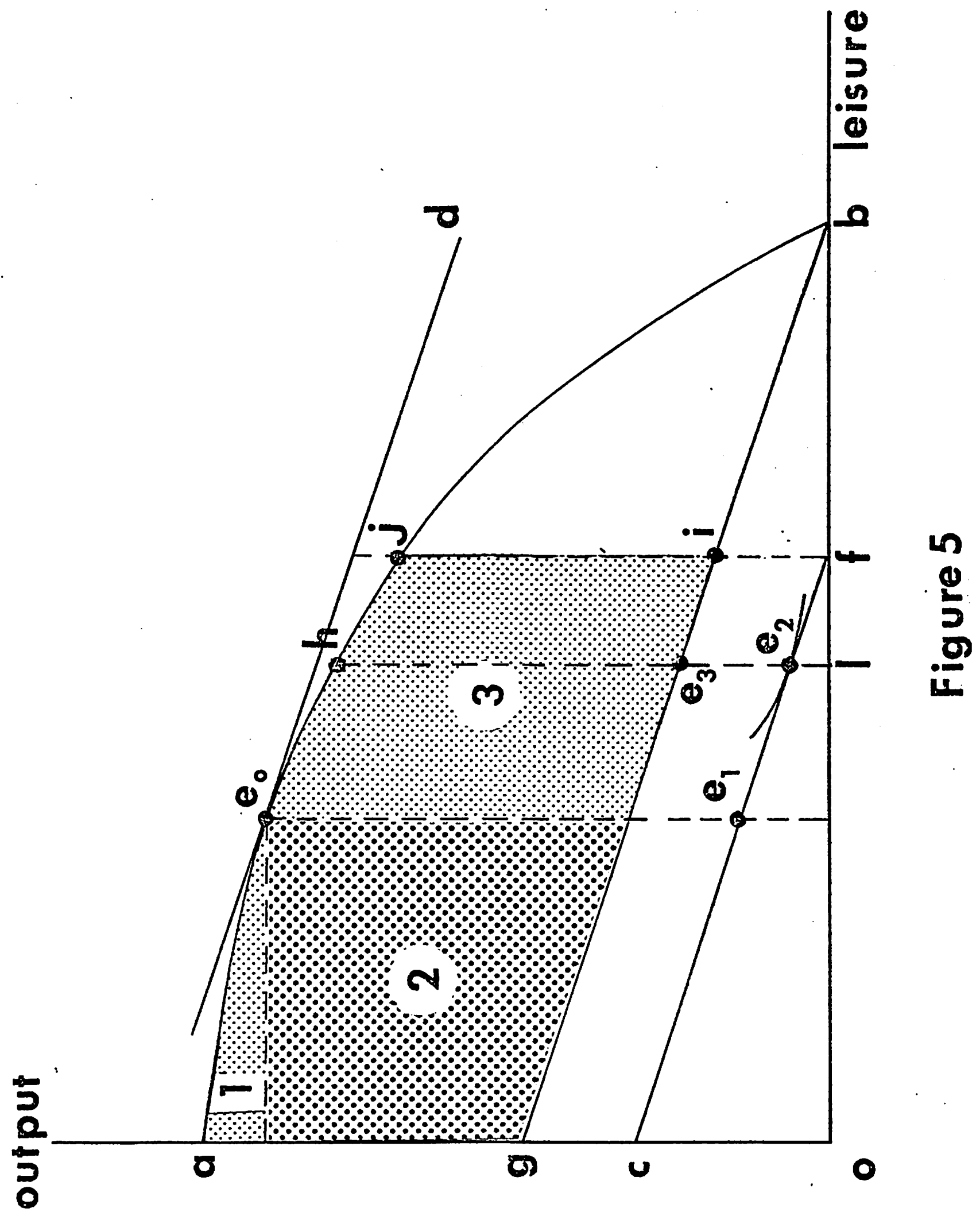


input and output) to the area agijhe in Figure 5. (The area $j$ ib is excluded since at least $f b$ of labor must be hired if $e_{0} d$ is to define an equilibrium wage from the point of view of small farmers.) The area agijhe。 can be subdivided into three zones (1, 2 and 3 ) defined by the relationship of the production ratios which prevail in each zone to the production ratios of the small farmers (given by the point $e_{0}$ ). In zone 1 , both the laborland and the output-land ratios are higher on the large, inefficient farms than on the small farms. In zone 2, the labor-land ratio is higher and the output-1and ratio is lower, and in zone 3 , both ratios are lower.

Only a production point in zone 3 is consistent with the empirical production ratio pattern. Unfortunately, there are no a priori arguments suggestIng that a general presumption of inefficiency leads to a production point in zone 3 rather than in either of the other two zones. Thus, inefficiency only provides for the possibility that production ratios correspond to the observed pattern; it is not a sufficient condition.

production and distribution implications of land reform can be examined in the context of an inefficiency explanation if the production point is assumed to lie in zone 3, as the empirical evidence suggests. Land reform under case A assumptions is illustrated in Figure 6 which reproduces the basic structure of Figure 5 for an economy without small farmers. Pre-reform equilibrium is characterized by a wage (given by the slope of the lines $e_{0}^{d}$ and cd), a production point $\left(e_{2}\right)$ and a point at which landless laborers are in equilibrium $\left(e_{1}\right)$.

If the pre-reform wage were to persist into the post-reform situation, an analysis similar to that embodied in Figure 2 establishes that equilibrium would be along ij, say at $e_{3} \cdot e_{3}$ does not, however, imply the equality 


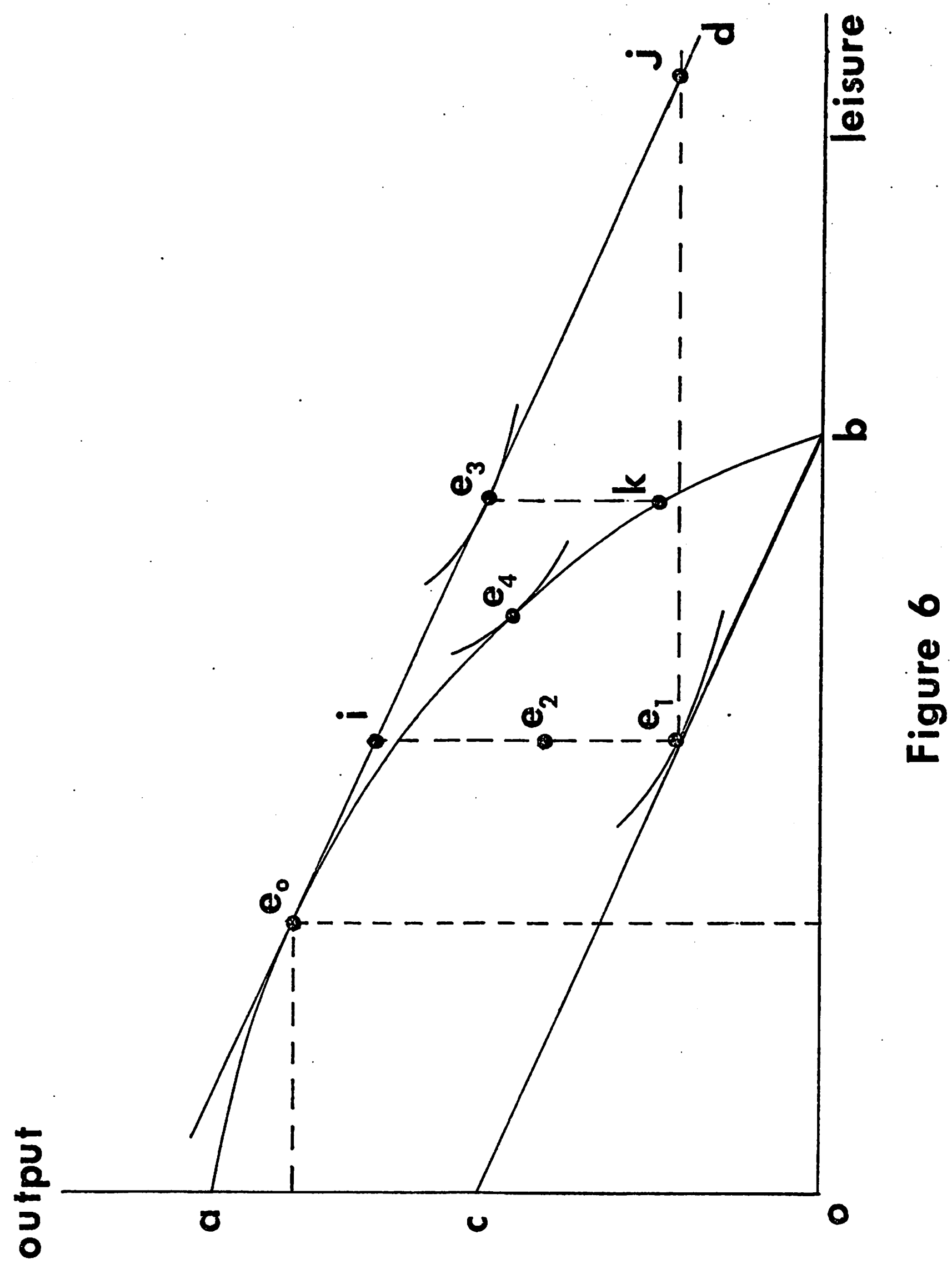


of the demand for and supply of labor, and equilibrium will finally be reached along $e_{0} k$, say at $e_{4}$. At $e_{4}$, more or less output may be produced in comparison with point $e_{2}$ (an increase in output is illustrated). It can similarly be shown, by analyzing the impact of 1 and reform on the demand for and supply of labor and on the intensity of cultivation, that output may or may not increase under case B. The wage must always rise, however, with the result that landless laborers are better off. 
TABLE 1

Measurement Market Failure Inefficiency Monopsony

\section{Case A}

output

up down

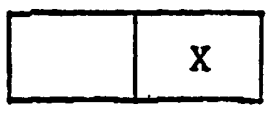

- 1andless laborer welfare output

up down
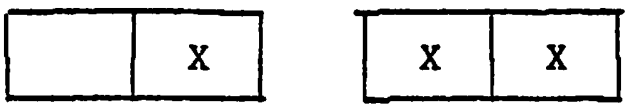

Case B

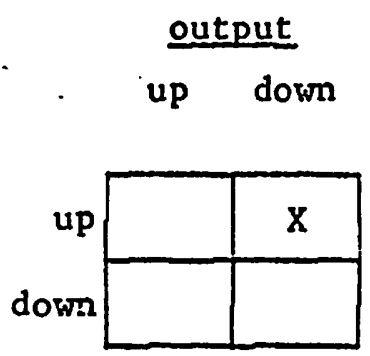

\begin{tabular}{|c|c|}
\hline up & down \\
\hline & $\mathrm{X}$ \\
\hline$X$ & $x$ \\
\hline
\end{tabular}

\begin{tabular}{|c|c|}
\hline \multicolumn{2}{c}{ output } \\
\hline up & down \\
\hline$x$ & $X$ \\
\hline & \\
\hline
\end{tabular}

output

up down

output

up down

\begin{tabular}{|l|l|}
\hline $\mathrm{x}$ & $\mathrm{x}$ \\
\hline
\end{tabular}

output

up down

\begin{tabular}{|l|l|}
\hline$x$ & $x$ \\
\hline & \\
\hline
\end{tabular}




\section{Partial Reform}

As is clear from the preceding discussion, any hopes for output gains are associated with the removal of distortions which characterize the pre-reform agricultural sector. This perspective immediately suggests that land reform, insofar as it affects distortions and does not just transfer factor ownership, can be related to the general theory of second best policies and distortions [Bhagwati, 1971]. In particular, since reform is not likely to be a first best policy, it is possible that it worsens the effect of a distortion. In this section, one example of this phenomenon is discussed.

Consider a very simple model of the agricultural sector in which the leisure decision is ignored for simplicity. Small proprietors (peasants, denoted $P$ ) have some land $\left(T^{p}\right)$ which they work using $L^{p}$ of their total labor $(\bar{L})$. In addition, these peasants do $L^{l}$ work on the land $\left(T^{l}\right)$ of large landowners (denoted $l$ ) who do not work themselves. These large 1andowners are in a monopsonistic position in the agricultural labor market. Each group produces with an identical production function (F) exhibiting constant returns on land (T) and labor (L).

Peasants maximize their income

$$
Y=F^{p}\left[T^{p}, L^{p}\right]+w\left(\bar{L}-L^{p}\right)
$$

which yields the wage equals marginal product condition

$$
\mathrm{w}=\mathrm{F}_{2}^{\mathrm{P}} \text {. }
$$

Landowners maximize their rents (R) subject to (2) since they are monopsonists 


$$
\mathrm{R}=\mathrm{F}^{\ell}\left[\mathrm{T}^{\ell}, \mathrm{L}^{\ell}\right]-\mathrm{F}_{2}^{\mathrm{p}}\left[\mathrm{T}^{\mathrm{P}}, \mathrm{L}^{\mathrm{P}}\right] \mathrm{L}
$$

which yields the marginal factor cost equals marginal product condition

$$
\mathrm{F}_{2}^{\mathrm{P}}-\mathrm{L}_{\mathrm{F}}^{\mathrm{l}} \mathrm{P}=\mathrm{F}_{2}^{\ell}
$$

Since $\mathrm{F}_{22}^{\mathrm{P}}<0$, the marginal product on peasant land exceeds that on landowner land. Hence the property of constant returns assures that the production ratios predicted by the model correspond to those which have been observed. Monopsony leads to agricultural output falling short of what is possible with given input endowment. A total 1 and reform which destroyed the monopsony power of large landowners would lead to maximum output. ${ }^{2}$ A partial land reform, represented by a small transfer of land from landowners to peasants can have the opposite effect of lowering total output $Q$

$$
Q=F^{P}\left[T^{P}, L^{P}\right]+F^{\ell}\left[T^{\ell}, L^{\ell}\right]
$$

Totally differentiating equations (3) and (5) and recalling that $T^{p}+T^{\ell}=\bar{T}$ and $L^{p}+L^{\ell}=\bar{L}$ yields

$$
\frac{d Q}{d T^{p}}=\left(F_{1}^{P}-F_{1}^{l}\right)+\left(F_{2}^{P}-F_{2}^{l}\right)\left(\frac{F_{21}^{l}+\left(F_{21}^{p}-F_{221}^{p} L^{l}\right)}{\left(F_{222}^{p} L^{l}-2 F_{22}^{p}\right)-F_{22}^{l}}\right)
$$

which may be positive or negative since from equation (4) and the usual assumptions that

$$
\frac{\partial \mathrm{MFC}}{\partial \mathrm{L}^{\ell}}=\mathrm{F}_{22^{\mathrm{P}}}^{\mathrm{P}} \mathrm{L}^{\ell}-2 \mathrm{~F}_{22}^{\mathrm{P}}>0
$$


(8) $\quad \frac{\partial M F C}{\partial T^{P}}=F_{21}^{P}-F_{221}^{P} L^{\ell}>0$

equation (6) has the sign pattern

$$
(t)+(-)\left(\frac{(t)+(t)}{(t)+(t)}\right)=? .
$$

Hence reform may worsen the impact of the distortion on total output. If reform is desired on the usual distributional grounds, it should be accompanied by a first best policy to mitigate the distortion. Various tax policies would be appropriate. 


\section{Compensation}

Payments by land reciplents either as compensation to former landowners or to the government always tends to favor increased output after reform. This result is a consequence of a mitigation of the output-reducing effects of the labor-leisure decision. We illustrate this general proposition by one example.

Consider a pre-reform situation of monopsony under case A assumptions. In Figure 7, the pre-reform wage is given by the slope of $e_{0} d$ equal to that of $c b$. Production takes place at a point such as $e_{2}$ since landowners equate the marginal product not with the wage but with the marginal cost of labor which exceeds the wage.

Now assume that all land is transferred to the landless laborers who are required to pay the pre-reform rents $\left(e_{2} e_{1}\right)$ of the landowners to either the former landowners or the state. The possibility frontier facing the laborers is given by shifting the curve ab down by the distance $e_{2} e_{1}$ to yield the curve $a^{\prime} b^{\prime}$. Post-reform equilibrium will be somewhere along $a^{\prime} e_{1}$ (revealed preference rules out $e_{1} b^{\prime}$ ). Both output and laborers' welfare will have increased in the post-reform situation. 


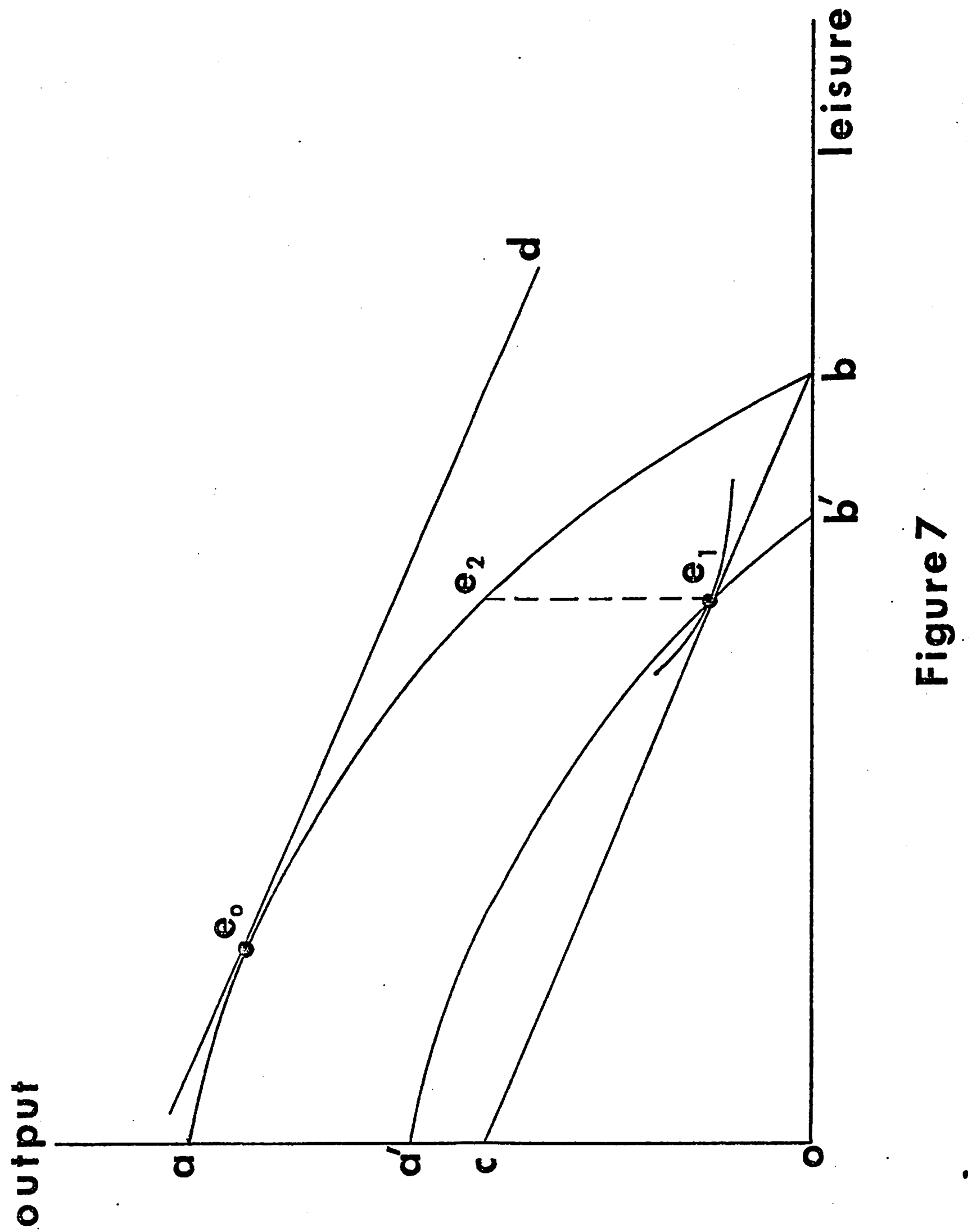


V. General Equilibrium Considerations

The implications for intersectoral labor flows following a reform are easily established. Assume that wages are initially equal between sectors, and that an inverse relation exists between wages and the quantity of labor input demanded in the non-agricultural sector. Recall the assumption of a fixed relative price between agricultural and non-agricultural goods. If the post-reform (actual or implicit) agricultural wage as determined above exceeds the pre-reform wage, labor will flow from the non-agricultural to the agricultural sector. This adjustment lowers the wage in agriculture and raises the wage in the other sector until wage equality is restored. The final wage will be between the pre-reform wage and the post-reform wage as calculated by the partial equilibrium analysis. Similar results hold if the partial equilibrium analysis establishes that the pre-reform wage exceeds the post-reform wage. Thus, general equilibrium considerations stressing the intersectoral re-allocation of labor following reform do not affect the qualitative conclusions of the partial equilibrium analysis.

of course, if the relative price of agricultural and non-agricultural goods is not fixed (say by international trade), further adjustments between sectors occur. The general presumption is that increased agricultural output w111 lead to a decline in this sector's terms of trade and a mitigation or reversal of the inflow of labor to the agricultural sector consequent on a rise in agricultural wages. A decline in agricultural output would have the reverse effect.

Thus, the output effects of a land reform have important implications for intersectoral resource allocations and possibly for the intersectoral distribution of total national income. Intersectoral transfers of income 
consequent on reform, although only sketched here, may be very important and illustrate why the output effects of a reform may be critical even when it is already established that landless agricultural laborers as well as recepients of redistributed land will benefit. Even more complicated models would take into account the potential impact of reform on urban unemployment. A rigorous formulation of these general equilibrium considerations is clearly important although it lies outside the scope of this paper. 


\section{Conclusions}

Table 1 summarizes the outcomes possible in each of the eight total land reform models considered. The heterogeneity of the results underscores the importance of the different explanations of the production ratio pattern. The optimistic view that reform leads to a rise in output and an improvement in the welfare of all groups other than expropriated landowners is a special case. On the other hand, the Berry result of an immiserization of the landless laborers can only hold in the context of market failure.

A further complication of the analys is was introduced by the model of a partial land reform. Other explanations of the production ratio pattern, other schemes of compensation (expropriation is implicit in our analysis) and other types of land redistribution (e.g. from small farmers to landless laborers) can be considered in the framework summarized in Table 1 . The clear implication is that any empirical attempt to project the outcome of a land reform must pay special attention to the particular cuases of the production ratio pattern. In addition, the labor-leisure decision, which plays an important role in inhibiting output increases after the removal of a distortion, needs to be explicitly considered in any empirical work.

Finally, in constructing our models we have been careful to define reform as simply a change in land ownership. This approach corresponds to Warriner's concept of a simple reform. As has been pointed out [Warriner, 1973], the historical pattern of output changes consequent on this type of reform has been rather mixed supporting our theoretical conclusions. On the other hand, wany actual reforms are encompassed by her category of integral reforms where redistribution is accompanied by the provision of many supporting measures (credit facilities, extension services, etc.). Any analysis of actual reforms must take these factors into account as well. 
NOTES

$1_{A}$ cheap capital explanation, although possible is not particularly plausible. It rests on the hypothesis that the larger a unit is in absolute size, the lower the interest rate at which it can obtain capital.

Assume all units produce output (Q) with an identical constant returns to scale production function using land (T), labor (L) and capital (K). All units face the same wage $(w)$, the labor market being perfect to avoid confusion with other explanations. The $i^{\text {th }}$ unit with given land holdings $\left(T_{i}\right)$ faces an interest rate given by $r_{i}\left[T_{i}\right]$ with first derivative $r_{i}^{\prime}<0$. The $1^{\text {th }}$ unit maximizes

$$
\pi_{1}=T_{i}\left\{q\left[l_{i}, k_{i}\right]-r_{i} k_{i}-w l_{i}\right\}
$$

where $\ell_{i}=\mathrm{L}_{i} / \mathrm{T}_{1}, \quad \mathrm{k}_{i}=\mathrm{K}_{i} / \mathrm{T}_{i}$ and $\mathrm{q}=\mathrm{Q} / \mathrm{T}_{i}$ yielding first order conditions

$$
q_{1}=w \text { and } q_{2}=r_{i}
$$

with second order conditions

$$
\Delta=q_{11} q_{22}-q_{12}^{2}>0
$$

Now, it is easily shown that

$$
\frac{d l_{1}}{d T_{1}}=-\frac{q_{12}}{\Delta} r_{1}^{\prime} .
$$

Thus, if the land-labor ratio is to rise as farm size rises, $q_{12}<0$, 1.e., capital and labor must be substitutes. 
Further, since the output-1and ratio must fall as farm size increases, we require $d q / d T_{i}<0$. But

$$
\frac{\mathrm{dq}}{\mathrm{d} \mathrm{T}_{1}}=\frac{\mathrm{r}_{1}^{\prime}}{\Delta}\left(q_{2} q_{11}-q_{1} q_{12}\right) .
$$

Now, if $q_{11}<0$ (diminishing returns) and $q_{1}, q_{2}>0$ and the second order condition is met, we must have $q_{12}$ sharply negative. Hence, substitutability between capital and labor is not adequate for this model to reproduce the empirical results -the substitutability must be such that $q_{2} q_{11}-q_{1} q_{12}>0$. Note further that this hypothesis is difficult of empirical verification since if $Q$ is a CES production function, $Q_{i j}>0, i \neq j$, if $Q_{i i}<0$. A more complicated functional form than CES must be used.

${ }^{2}$ A total reform in which leisure effects are considered leads to the same results as under the inefficiency model of Section IIC. These results are recorded in Table 1 and can be derived from a comparison of pre-and post-reform labor demands and supplies as in Sections IIA-C. The labor-leisure consequences of factor ownership changes are the important factor making for the possibility of output declines. 
REFERENCE LIST

Berry, R. A., 1971, 'Land Reform and the Agricultural Income Distribution', Pakistan Development Review, Vo1. 21, no. 1 .

Bhagwati, J. N., 1971, 'The Generalized Theory of Distortions and Welfare', in: J. N. Bhagwati et al., Trade, Balance of Payments and Growth, Amsterdam: North Holland.

Cline, W. R., 1970, Economic Consequences of a Land Reform in Brazil, Amsterdam: North Holland.

Dorner, P., 1972, Land Reform and Economic Development, Hamondsworth: Penguin.

Dorner, P. and Kane1, D., 1971, 'The Economic Case for Land Reform', in: P. Dorner (ed.), Land Reform in Lat in America, Madison: I,and Economics.

Long, E. J., 1961, 'The Economic Basis of Land Reform in Underdeveloped Countries', Land Economics, Vol. 37 , no. 2 .

Sen, A. K., 1966, 'Peasants and Dualism with or without Surplus Labor', Journal of Political Economy, Vol. 74, no. 5.

Srinivasan, T. N., 1972, 'Farm Size and Productivity Implications of Choice under Uncertainty', Sankhya, Series B, Vol. 34, no. 4.

Warriner, D., 1973, 'Results of Land Reform in Asian and Latin American Countries', Food Research Institute Studies in Agricultural Economics, Trade and Development, Vol. 12, no. 2 . 